\title{
Sources of inequality in South African early child development services
}

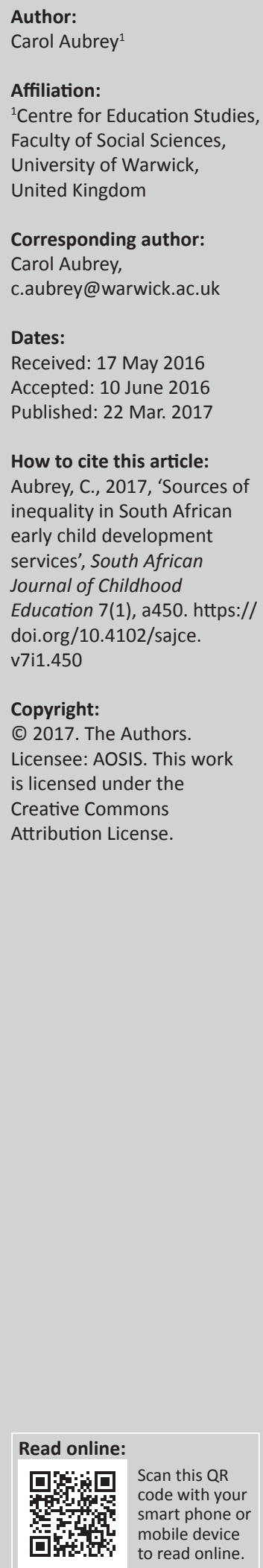

This article seeks to examine critically South African early child development (ECD) in order to uncover some of the challenges that lie ahead in creating a more equitable future for its youngest children. An investigation of play and learning within varied ECD contexts, using observation and interview, is presented. The social constructionist approach adopted allowed exploration of play and learning from the perspectives of a range of stakeholders. Three themes, role of play, sources of inequality and barriers to play, are interrogated. The role and contribution of the concepts of readiness, needs and play to maintaining unequal treatment of vulnerable children are identified. The possibility that these concepts may serve as mechanisms to reproduce social and cultural inequality is considered.

\section{Introduction}

South African policy to promote early child development (ECD), birth to 4 years, has been moved forward through the first decade of the twenty-first century by the National Integrated Plan for Early Child Development in South Africa 2005-2010 (Government of South Africa 2005). The purpose of the integrated plan has been to implement ECD services for young children, and in particular vulnerable young children, at national, provincial and municipal levels. This plan has been revised and lessons to be learned identified (Department of Basic Education 2013), with a priority being to provide universal access to Grade R for 5 to 6-year-olds by 2014.

ECD services in South Africa, however, are realised largely through the private and the non-profit sector, through non-governmental organisations (NGOs), community-based organisations (CBOs), individual crèches and preschool centres, and other stakeholders that may involve parents and caregivers. They also include home-based ECD programmes with home visits from trained Family Community Motivators (FCMs) and informal playgroups provided by NGOs, particularly in rural areas.

Although government funding for ECD has increased, estimates of non-enrolment into preschool or other ECD activities have been as high as 70\%. Ngcobo (2013) noted a lack of reliable data on the number of children enrolled, the state of infrastructure and levels of staff qualifications. Suffice it to say there is a strong need for integrated, quality ECD services, particularly for the poorest families.

Meanwhile, a final draft of the National Curriculum Framework Birth to Five (Ebrahim \& Irvine 2012) has been agreed. This draws on the values in the Constitution, principles set out in existing policies, plans and curricular reviews, literature searches and stakeholder voices in the field. Twelve principles cluster round three interacting themes that unite the child:

- as a competent person

- whose learning and development are important

- who needs strong connections with adults.

For the purpose of this article, the focus will be on Theme 2 (My learning and development is important). This is underpinned by four principles:

- learning by taking up opportunities to make meaning about the world

- using local and indigenous knowledge and skills to promote socially, culturally and linguistically sensitive learning environments

- enhancing learning and development through play and hands-on active experiences

- a comprehensive ECD learning programme for quality and equality of opportunities.

It is the intention of this article to examine critically these principles, in order to uncover some of the challenges that may lie ahead in attempting to create a more equitable future for South Africa's 
young children. This will be attempted through interrogation of observations and interviews carried out in ECD contexts in the rural KwaZulu-Natal Midlands region and in the outskirts of Durban, represented by an NGO providing resources and training, a voluntary Roman Catholic charitable $\mathrm{CBO}$, and a private day nursery and preschool.

\section{Equality for all children?}

As noted by Hall et al. (2012) equality is a founding value of the South African Constitution and a fundamental right, but what does this mean in practice for children? As will become clear in this section, however, treating everyone the same may not address deep-seated discrimination and socioeconomic disadvantage.

In fact, income inequality has continued to rise since the end of apartheid. This is related to high rates of unemployment and inequality in wages. Hall et al. (2012) showed that in 2010, 60\% of South Africa's 18.5 million children lived in households with an income of less than R576 per person per month, with the gap between rich and poor widening. Furthermore, two-thirds of black children live below the poverty line, compared with $2 \%$ of white children. In poor households, inequality has many aspects and it can lead to poor heath and poor educational outcomes. Very young children growing up in the former homelands, for example, may be subject to multiple deprivation, despite high investment in public education and high school attendance. It would seem that further investments in ECD services have a powerful role to play. The United Nations Convention on the Rights of the Child (UNCRC) (UNICEF 1989) advocated the protection of rights (and special needs) of all children to an environment where they can grow and reach their potential with access to social services; legal, health and educational systems; play; and freedom from work.

If ECD is to contribute to a more equitable future, however, it will need to avoid practices that merely privilege those children already positioned more powerfully by social and cultural capital, race, gender, age and access to English language proficiency. As noted by Ryan and Grieshaber (2005), injustice can be maintained through everyday assumptions in structures and practices, social relationships and discourses that serve to privilege some groups and exclude others. Socio-economic, religious and cultural differences, as well as varying levels of education in families of young children, challenge ECD practitioners to create environments that incorporate diversity and more equitable strategies (Grieshaber 2008). In this context, play and its association with learning and development in young children may be contested and rejected as incompatible with nonWestern beliefs of childhood, child-centred approaches and individualism (Brooker 2002; Burman 2008). The notion of play, progress and child development is so deeply embedded in Western culture that the educational benefits as well as the pleasure to be derived from play are simply taken for granted (Sutton-Smith 1997). However, Sutton-Smith has also drawn attention to 'dark play'. Walkerdine (1984), for instance, identified the power relations involved in children's play and interactions with one another and with adults. In this sense, 'play' may involve conflict and concession, and power may be played out through means that relate to age and size, gender, socio-economic status or any number of other factors that impinge on children's play. This means that there may be winners and losers, beneficiaries who are already positioned more favourably and those who are marginalised. The implication for this article is that play and active learning in educational contexts can be a source of inequality; thus, the broad intention is to offer alternative ways of thinking about and challenging ECD and its relationship to play, learning and social justice.

\section{Theorising early care and education and the young African child}

As noted by Pence and Nsamenang (2008), African ECD has been too little theorised. Penn (2005) has drawn attention to the widely cited Developmentally Appropriate Practice in Early Childhood Programs (Bredekamp \& Copple 1997) of the National Association for the Education of Young Children, purporting to offer neutral guidance on quality childcare, which drew heavily on child development evidence from the USA. This text has served as one focus for more general criticism of Western ECD programmes and practices that have been inappropriately applied in the South by major international donor agencies (Serpell 1993; Viruru 2001). These writers draw particular attention to play-based pedagogies that presuppose an unrealistic level of material resourcing unattainable in the South. As noted by Gielen and Roopnarine (2004), culture, context and diversity are ignored by Developmentally Appropriate Practice (DAP) approaches in favour of 'homogenised' Euro-American approaches that arrived with colonisation. The postindependence situation in South Africa, however, has presented a very distinctive political and socio-economic climate in which contradictory discourses have struggled for ascendancy. Independence and globalisation have brought new risks to vulnerable children exposed to greater financial instability, migration and contagion from HIV / AIDS (UNDP 2014) but also new possibilities for intercultural dialogue, exchange of knowledge and practice (Kaur, Quinlivan \& Boyask 2009). Despite strong policy emphases on promotion of rights-based approaches to children's well-being (Dawes, Bray \& Van der Merwe 2007), interconnectedness and indigenous practice (Nsamenang 1992, 2004), growing global inequality and the spread of neoliberalism, with its focus on individualism and competition, performance and accountability for learner and teachers, serve merely to increase inequalities and reduce the range of what counts as quality education or preschool education (Robertson 2014). Traditional African educational ideas and practices that stress learning through participatory pedagogy and processes of home and community care as well as peer culture with little direct instruction (Nsamenang \& Lamb 1994) may sit uneasily with expectations of the most economically privileged African families who want their 
young children to have the best resourced schools, the most experienced teachers, the smallest class sizes, rounded curricula and an engaging pedagogy (Gorski 2014).

The challenge lies in thinking or rethinking how common models of ECD and 'best practice' can be devised in the face of such diverse developmental niches (Harkness \& Super 1992) in a newly meritocratic society. The need for a local indigenous community-sensitive approach to child wellbeing is recognised, but at the same time a wealthy and economically privileged minority see their children in terms of economic investment in a neoliberal society.

The need for reconceptualising child development has been recognised for some time from the North (by work of Pence 1998; Penn 2005; Woodhead 1996) and the South (in work of Nsamenang 1992, 2001, 2004; Serpell 1993; Viruru 2001). In this respect, most promising has been the post-structural approach that has placed under the critical spotlight the foundation disciplines of ECD, influenced by the work of Michel Foucault. By exposing the reciprocal relationship among power, knowledge and institutional structures, a space is created to hear other voices, not privileging one over another and, at the very least, broadening and deepening a debate in which childhood itself can be understood as a social construct and socialisation of that child as a function of culture, context and diversity. Indeed, a variety of critical theories that include feminism, post-colonialism and postmodernism have been mobilised as part of a movement to reconceptualise ECD in the South.

\section{Questions}

As noted by Ebrahim and Irvine (2012:11) a distinctive feature of ECD in South Africa is 'the urgent need to effect social transformation ... for the youngest children'. Drawing on Theme 2 of the draft new curriculum and focused on young children's learning and development, its underpinning principles raised important research questions for this article to address:

- What is the role of play in young South African children's ECD experiences?

- What (if any) are the sources of inequality in such play experiences?

\section{Methodology}

Social constructionism provided the philosophical underpinning for this study. It was positioned to explore constructions of play in South African ECD from the perspectives of a range of stakeholders in KwaZulu-Natal. The purpose was to investigate play in ECD from the perspective of ECD practitioners and children by conducting a range of ECD practitioner interviews and video-recorded observations of daily routines in a range of preschool settings, urban and rural. Children's views on preschool were sought through a trusted adult, who also acted as interpreter where necessary. Interviews were audiotaped and transcribed. Video-recordings were downloaded and archived each day. The study thus investigated play in ECD as built up from the perceptions and social actions of the participants themselves. It included the reported organisational structures and positions, behaviours of the social actors themselves and social activities that emerged in social interactions in daily routines and practices.

The ontological position adopted, whilst founded in constructionism, was not an extreme relativist position denying the existence of an external reality but one allowing for a variety of interpretations to be made of the way ECD play was understood or interpreted, as co-constructed in the social actions within the ECD organisation concerned that could not be planned in advance. Social constructionism has its roots in the work of Berger and Luckmann (1991). As noted by Stainton Rogers (2011:42), it is not just about describing alternative social realities, it is about gaining insight into and understanding of the means by which 'realities' are constructed and the uses for which they are deployed. The notion that constructed realities emerge in historically and culturally situated social processes is consistent with the values underpinning the new National Curriculum Framework for South Africa (Ebrahim \& Irvine 2012) that saw the need for social transformation both in the context of historical inequalities and in order to create a new vision for citizens in democratic South Africa. Hence social constructionism is characterised by the social aspect of meaning-making through traditional rules, practices and African languages that determine what is agreed as 'truth' within a particular community (Burr 2003).

\section{Methods of study}

The main thrust of the study was to investigate the role of play as a potential source of inequality within the varied ECD contexts. Enactment of play was the primary focus of the participants, who constructed their knowledge of play in ECD within specific settings. However, the researcher was also implicated in the shared construction of this knowledge through the data-gathering and analytical procedures that were framed within a particular social-historical and cultural context. The observation method attempted to capture the daily routines within which the study participants operated and the ECD play processes were enacted. The individual interviews provided the wider context of ECD structures and discourses.

In terms of sampling, a maximum variation sample of preschools was the aspiration as shown in Table 1.

TABLE 1: Preschools and practitioners who took part in the study.

\begin{tabular}{|c|c|}
\hline Preschool & ECD practitioner interviewed \\
\hline $\begin{array}{l}\text { Private nursery, preschool and crèche } \\
\text { (urban) }\end{array}$ & Manager (qualified to NQF Level 4) \\
\hline NGO-supported preschool (rural) & $\begin{array}{l}\text { NGO lead trainer (trained primary teacher } \\
\text { and ECD practitioner (qualified to NQF } \\
\text { Level } 4 \text { ) }\end{array}$ \\
\hline $\begin{array}{l}\text { NGO-supported family facilitator with } \\
\text { group of children and an older 'buddy' } \\
\text { (rural) }\end{array}$ & $\begin{array}{l}\text { Family Community Motivator (basic NQF } \\
\text { Level } 1 \text { qualification) }\end{array}$ \\
\hline $\begin{array}{l}\text { Charity-based preschool for destitute } \\
\text { children and families (urban) }\end{array}$ & ECD practitioner (unqualified) \\
\hline
\end{tabular}


The sampling strategy led to a maximum variation sample in preschools selected for observation and in participants who agreed to be interviewed. One day was spent in each setting with introductions secured in advance and ethical clearance forms signed subsequently.

A digital video camera was used to film the daily programme in each setting. Unstructured field notes were also taken against a timeline to provide contextual information. At the end of the observation, semi-structured interviews took place with the relevant ECD practitioner. Open-ended interview questions were devised to allow exploration of the key research questions and as a basis for flexible conversations with the participants concerned. All interviews were transcribed and returned for verification and were hence available for textual analysis. A process of analysis and reduction produced a condensed version of highlights, stripped of repetition but preserving the full range of activities.

Data were originally gathered in August 2007 and analysed in January 2008, with findings presented at seminars in Stellenbosch, Melbourne and Sydney. Cumulative analysis of policy statements, individual interviews and observations led to identification and cross-referencing of key themes in a grounded manner. The findings have been regularly shared with master's students following the 'Childhood in Society' course at the University of Warwick, UK. Data have been extensively re-analysed and reworked for this article.

\section{Analysing and interpreting}

Analysis of data, visual and text, as a proxy for the direct experience was qualitative and hence amenable to thematic analysis (Ryan \& Bernard 2000). Each video sample and interview was read or watched several times with a view to finding themes in chunks of text or video clips. The researcher was looking for processes, actions, assumptions, conflicts, contradictions, repetitions and/or how participants 'managed' social relationships and solved problems. Code books were then created to list themes or categories, describe and determine the inclusion/exclusion criteria and, finally, establish what label or value was placed upon the theme or category. This led to consideration of the ways in which the two different datasets were linked or associated - in other words, testing one data set on another, through comparison and contrast, as in the grounded theory approach (Corbin \& Strauss 2008). This involved triangulation where accounts of participants with different roles were sought, in order to reach an agreed position. On other occasions, the two data sets served complementary functions. With respect to social justice, for instance, the interview data set from one ECD setting made references to consideration of children's rights, whist the observation data set allowed consideration of the potential social inclusion or exclusion that actually occurred.

So far as possible the analysis adhered to special trustworthiness measures (Lincoln \& Guba 1985) such as prolonged engagement, allowing sufficient time to build trust and understand the culture, persistent observation in order to establish salient and pervasive features, subsequent peerdebriefing through conference presentation, an audit trail to ensure that the research processes and products were carefully documented and stored, and thick descriptions reported to illustrate the minimum elements of the environment needed and range of information required to provide the database.

\section{Ethical Consideration}

Ethical procedures of the British Psychological Society (2008) related to conduct, consent, confidentiality and debriefing were followed and agreed with ECD practitioners in advance. Written consent to participation was obtained, including agreement about the ways visual data were to be obtained and used. This acknowledged that visual images could identify individuals in the research dissemination process but included agreement that Internet use should be excluded. Particular considerations were necessary with respect to involvement of young children. The involvement of children and young people in decisions that bring about change in their lives should be located within the context of the international rights-based framework of the United Nations Convention on the Rights of the Child (UNICEF 1989). Children are increasingly recognised as social actors in their own rights (James \& Prout 1997) and central informants of their own lives (Christensen \& James 2008) in areas where their voices have traditionally been unheard (Alderson 1995; Alderson \& Morrow 2004). For researchers, particular methodological and ethical issues can be involved, associated with negotiating entry to their lives and domains, as well as the roles and relationships and processes entailed. Bearing in the mind the age of the children concerned and the nonparticipative role of the researchers, caregiver agreement to children's role in the research was negotiated through the preschools. During observation visits, the researcher and colleagues kept a low profile in order to avoid disturbing ECD activities that were well supported by the ECD practitioners involved. Ongoing monitoring of children's responses was established in order to ensure there were no signs of discomfort or unease that could be attributed to researchers' presence.

\section{Results}

At the first stage of analysis, a priori themes derived from the research questions were identified. These focused on the role of play and the sources of inequality from which multiple meanings emerged. At the second stage of analysis, a third theme emerged that coalesced from analysis of ECD practice barriers to play.

Accordingly, the three themes will be scrutinised separately although, where appropriate for the purpose of discussion, their close interrelationships will be highlighted.

\section{The role of play}

All practitioners described the children's activities as 'play', though emergent meanings and understandings differed. The manager of the private preschool saw the children's activities in terms of a well-planned and highly professional 
educational experience, a service for which 'appreciative' prosperous working Indian parents paid. Moreover, families were supportive of the wider social responsibility taken by the organisation to raise funds to offer free places to 'special' African orphans in the local children's home to 'give them their dignity .... and so that they could later go out into the world' (interview with manager).

By contrast, the NGO trainer serving vulnerable children living in poor rural households and communities, often from dysfunctional families affected by HIV and AIDS, defined play as 'respite':

They have a right to a childhood. They don't have to be little adults with all their responsibilities and doing of chores. For me, it's important for these children to have time where they can get into a fantasy world and just be normal kids, not having to fetch wood, care for the sick, do all of that. It's so important, probably more important than for those other children whose lives are very easy. (NGO trainer)

This was a definition very much in line with the UNCRC (UN 1989), in which every child is accorded the right to relax, play and engage in leisure activities (Article 31) and the right to protection from child labour that might harm health and education (Article 32). As the NGO trainer reflected, 'based on practice, you have to go back to children's rights ... then compare existing practice with children's rights'.

The NGO-supported teacher and FCM both stressed children's enjoyment of playing with caring adults, in a context of overwhelming deprivation, despair and lack of emotional energy for child-rearing. As noted by the NGO trainer:

We've got some people sitting, gazing into space when we first started working with them ... breakdown of the extended family, high unemployment, orphaned children with grandparents, only the very young and the very old ... Nobody wanted to play, anyway ... last thing anyone needed ... with no social structure, no meals, no source for clean water, sanitation. First, we had to look at the whole community. It was building capacity with women, finding relevant documents in order to access social grants, improving health, seeking medication for HIV/ AIDS, building veggie gardens, changing the environment through collective responsibility.

In an ideal world, you would work holistically with the whole environment ... social-emotional stuff, families, food, nutrition, clean water, bringing in the fathers, the economic development of families. If you don't change that environment - the family and environment, working out in concentric circles of child, family community, you're not really changing things. For these kids coming to preschool for 3 or 4 hours a day doesn't really change anything if they go back home to no stimulation, doing chores, no balanced meals, no clothes. It doesn't help to go to preschool but it does give respite during the day and it's a lot for them. ( NGO trainer)

The NGO-supported teacher recounted discussion of families that might stimulate a child to bring in a photograph of a mother who had died and where caregiving was provided by many people who were aunts and uncles. A ring discussion of news of what happened at the weekend could occasion the response:
'I went to a funeral ...' (Rural preschool child)

... and I'd ask 'How did the funeral go, can you tell me?' to which she said 'people were crying and my mum told me someone had passed away'. (Rural preschool child)

In such circumstances, as the NGO trainer recounted, children's role play involved death. Such was the stuff of reenactment in the domestic play area.

\section{Sources of inequality}

Communities of young children and families in circumstances of urban and rural disadvantage, those most in need and most deserving of high-quality ECD facilities, were reported to have the most difficulty in accessing the resources needed to realise this. For example, as the NGO trainer stressed, only the most needy rural families could have access to the FCM. These FCMs would be equipped with some play skills. None of these women and few of their children had ever had educational toys or equipment of their own. The aim of the FCM, however, was to teach children to do puzzles, to colour and to cut. So far as possible, however, approaches were based round traditional stories and rhymes as this was 'part of their culture'. The hope was that play would continue after the facilitator had left, drawing on toy bags that were loaned and toy libraries that were being developed. FCMs also worked with two or three older 'buddies' aged between 10 and 14 years who committed to hours of playing games with young children in the home or collectively.

Toy bags were reported to be changed once a month, though resources were observed to be meagre and limited to a small supply of Lego bricks, puzzles, balls and 'push' toys. A bag of toys was planned for a family of children but in practice this was insufficient for a group. Asked what she would change about her work, the family facilitator responded that she would wish to have more toys for children to play with. A similar picture was observed in the charity-based preschool, where children's Lego brick construction material was limited, though children did have access to painting material, paper and felt pens to practise writing patterns.

A common daily programme was adhered to across sites:

- free play

- 'ring time' for discussion

- song and movement, and story

- snack time

- outdoor activities.

A stark contrast was observed between the modest facilities of the NGO-supported rural preschool and the abundance of play resources in the private urban preschool. In the private preschool, outdoor toys and furniture included water play, swings and a climbing gym for gross motor activity on a manicured and watered lawn, whilst inside there was opportunity for communication and reading, fantasy play, painting, felt pens, scissors and crayons in the creativity area, vehicles and construction materials, puzzles, fitting and 
matching activities. Nevertheless, children across settings were unanimous: 'we like everything here in preschool, the food, the toys ...'; 'we like very much to write and to draw'.

The NGO-supported preschool was also observed to be equipped inside with limited resources for fantasy play, block and creative areas. In the outside area, swings were crafted from old car tyres; hula hoops and balls were available. However, water was scarce in the dry Midlands area; hence a very small quantity only was available in a plastic paddling pool for six children's eager exploration. In contrast to the rich first-hand experience that the privateschool children brought into their preschool, the NGOsponsored preschool children were observed to use posters and pictures for questions and discussion with an imaginative preschool teacher:

the qualities a preschool teacher must have are to use posters, use colours and pictures of other children, have general knowledge, be a patient, lively person with lots of love, lots of time ... (Rural preschool teacher)

The charity-based and NGO-supported preschoolers were observed to receive appropriate preschool activities, respectful of their indigenous culture, delivered in the isiZulu language and incorporating traditional games, ring songs, movement and dance. Cultural practices that valued learning by heart and repetition were still accorded a prominent place. Children were observed reciting the alphabet and counting in English; they joined in communal refrains within songs and heard stories read aloud in isiZulu.

Zulu parents, however, were reported by the NGO-supported teacher to prefer their children to be taught in English. Whilst she stressed that children were introduced to English by stages', competence in written English as reflected in labelling areas of the room for incidental learning to take place (for example, 'queit area' for quiet area) was poor. However, the main source of the printed or written word was books. Though a lavish library corner furnished with poems, stories and rhymes was available at the private nursery, this was not the case for the NGO-sponsored or charity-based preschools.

By contrast, the private preschool children received Englishmedium instruction that would stand them in good stead for formal schooling. Moreover, the promotion of Western values and practices was highlighted by a formal graduation ceremony from preschool or 'mini-debs ball' that was staged annually. The programme for this event provided advertising space for the businesses of the graduates' extended families, illustrated with a dancing Disney prince and princess couple.

The private preschool children had access to ECD programmes from highly trained ECD professionals who were reported to be appointed only following 'stringent screening' of both their 'qualifications and passion for the job', and with opportunities for external workshops and courses. In contrast, the qualifications of voluntary and home-based sector professionals were more variable, from appropriate National Qualifications Framework training for
NGO staff to unqualified staff at the charity-based preschool. Moreover, given the remoteness of their geographical location and targeted eligibility requirements, due to limited resources young children served by the non-profit sector inevitably experienced barriers to attendance at the preschool programme. At the same time, though parents could not always afford to pay the fees these children were nevertheless still accepted. Even where participation was possible, children were likely to walk long distances, often alone, and for home-based interventions there was a higher likelihood of weekly rather than daily input.

In terms of diversity, the non-profit ECD provision was tailored to the needs of the children and the families concerned. It was responsive to the whole child, the home language background and the community's culture. Integrated services were offered to support health, nutrition and social well-being in an environment that respected and supported diversity. Meanwhile, the for-profit sector offered an integrated range of children's services for professional families that acknowledged their own role as the first and main providers for their children, who welcomed the opportunity to be involved as active participants in the increased educational attainment of their children.

In terms of equity, whilst the South African aspiration is for opportunities for all children, regardless of family status, income, disability, gender, national origin, ethnicity, religion or race, to attend high-quality ECD programmes, those families and communities with fewest resources were yet to be fully served. There was evidence of flexibility in the ways in which integrated services were provided in both the forprofit and non-profit sector. The for-profit sector catered for young children from 06:30 until 17:30, providing a range of extracurricular activities, aftercare and transport for those able to pay. Whereas the non-profit sector supported the whole child and family and the community culture, it struggled to distribute basic centre-based and non-centrebased ECD programmes in poor and remote areas.

\section{Barriers to play}

What emerged from analysis of both observation data and reports of practitioners in the NGO-sponsored and charitysupported settings was a tension between provision of play experiences as a means to foster learning and development and an expectation, particularly from parents, that children should be prepared for Year R at school. For the charity-based preschool practitioner, learning to play and behave with other children constituted social preparation for school entry in the following school year.

I try to teach them how to play, how to behave with other children. 'If I say sit down, you must sit down. If I say I'm talking to you, you must listen. You must be quiet, get everything done now and play.' I try to train them to love each other, don't fight with other children ... All those things and sometimes for school, how to write and sometimes, drawing. (Charity-based preschool practitioner) 
Observation revealed her preschoolers preparing for school entry by chanting the letters of the alphabet, counting in English and practising visual-motor skill exercises.

The NGO trainer confirmed that the school readiness programme included 'colouring, matching, getting used to engaging with stories, music, drama, more free play, then story time, always a formal story time'.

The NGO-supported preschool teacher stressed that school readiness activities were also an expectation of Zulu parents, grandparents and other caregivers. Families, she reported, felt that if their children were settled in preschool and were used to being in groups of many children, then they would settle easily into school. She noted that preschool provided a basic education, although parents regarded preschool activities as 'all playing'. Parents expected children to learn how to write their names and know colours, 'like in school'. When meetings with parents were called, it was felt that they came 'to check the way their children learned'.

Asked what she regarded as the most important aspects of preschool, she admitted, 'we don't have papers and pens and things to write with so they don't write'. She did not see that it was her role to teach reading and writing, even though parents wanted it. Most important to her were the children's physical and social-emotional needs. She enjoyed talking and listening to children. Really important was for children to trust her and for her to show them love. Everyone wanted her attention and when she was a young teacher the hardest thing was not having enough time for each individual. Most important of all, she felt, was for children to have love and food in their tummies.

The FCM also reported that she was mindful of what children needed to know when they went to school:

We teach them to count, teach them colours, to sing like other children ... They must be like other children who go to school. They're learning to socialise so that when they go to school they will be like other children. (family community motivator)

Her children, too, were observed rote-counting in English, joining in with choral responses at key points in storybooks that she read to them. At the same time, she acknowledged that 'sometimes clothes and food come first and these are given to the children'. She stressed more than once that she liked children to wash and keep clean - 'I concentrate on personal hygiene because they're not really getting that at home'. Sometimes she observed that when she tried to play with children she could see that they were listless because they were hungry - 'they just go to sleep when they're playing because they're hungry'. The children themselves commented, 'we like preschool because we get food'; 'we like it because she gets us food'.

There was always a balance to be maintained between demonstrating children's physical and social-emotional needs to parents and, at the same time, ensuring their preparation for the next stage of school entry. When the children saw her arrive they became very excited and ran to grab her. She reported that she taught parents that children needed attention all the time. They needed love. Children had the right to family protection in an environment where they could grow and reach their potential.

As the NGO trainer explained, for the 20 FCMs working for her organisation at the time, the community had to be the focus. Her wish was for children to grow up in a community that nurtured them and allowed them to develop holistically, not just their cognitive development. For vulnerable children, development must be holistic, including social-emotional. Their professional role was to change children's immediate environment, their family and their home. The community they lived in must take responsibility for all the children and not allow some to 'fall through the gaps'. In the end, as a community they could then say 'every child is our child'.

The manager of the private organisation also stressed that she offered a holistic development with qualified and experienced staff, balanced meals, well-equipped indoor and outdoor areas and jungle-gym facilities with extracurricular activities - computers, speech and drama, dance classes, girl guides for older children, educational outings, balls, concerts and family 'fun days'. The crèche served professional working parents, catering for babies 3 to 12 months and children under five, as well as pre- and after-school care for children up to 12 . Indeed, the organisation provided for every conceivable 'need' of an affluent, aspiring and upwardly mobile professional class, including a seamless graduation to primary school. This included ensuring readiness for formal schooling.

\section{Discussion}

To revisit the research questions, firstly, what is the role of play in young South African children's ECD experiences? Play may not always be the best way to learn, as it may serve merely to reflect or reproduce society in terms of race, gender, social, economic and cultural capital, and proficiency in English (Grieshaber \& McArdle 2010). The focus on educational play in the private preschool, for instance, revealed how some children positioned themselves more powerfully at the expense of others (Sutton-Smith 1997). This was illustrated most tellingly in the contrast between snack time and free play. During snack time, the preschool teacher organised the seating arrangements so that there was one African orphan child sitting with each group of Indian children. When the children moved into a free-play session, however, the Indian children reconstituted their small-group cooperative activity, excluding the African children, who sat isolated at a separate table. In the NGO-supported preschool, an underage child observed in the preschool group drifted on the margins of the activities, looking, listening and waiting, and at lunch time, whilst the rest of the children ate in small groups chatting noisily, he sat on the floor alone, with a large bowl of food on his knee. 
Secondly, what (if any) are the sources of inequality in such play experiences? South Africa has the challenge of educating vulnerable preschool children whose home and community environments cannot easily provide high-quality care and stimulation. Fostering physical and cognitive development in this context requires a strong disposition towards providing a supportive environment and resources for growth, health, nutrition and social well-being, in an environment that respects diversity. Such a cast of mind contains strong elements of child advocacy and children's rights, but how sufficient is this view? Children acquire the everyday conceptual tools and knowledge handed down to them by their own culture, but how is the vulnerable child to be lifted above the competence that arises from the home and community environments? Preschool practitioners working in conditions of extreme inequality described their ideal in terms of comforting and nurturing, thus assuming an identity of early educator as 'mother figure', in sharp contrast to the notion of the private preschool practitioner as a professional with agreed qualifications and ongoing professional development. The danger lies in simplifying and narrowing educational goals in conditions of adversity that serve to reduce educational choice and run the risk of eliminating goals that might take children beyond their current experience and interests. How does the practitioner incorporate a broad perspective on cultural knowledge and tools and prepare the way for skills that will be needed for success in school? As the NGO-sponsored preschool teacher reported, the community elders and parents expected their children to write and learn English - 'when they are playing, they think that it's just a waste of time'.

Children marginalised by size, age or race may be excluded most during those times when they are less observed or freer of adult control and when corresponding unfairness or injustice is more likely to go unobserved. Ryan (2005) has shown how play and freedom of choice carry political and power dimensions, key elements of which are identified as toys, friends, the environment and allocation of time, as noted above. Equality of opportunity for all may not be enough. Valuing diversity helps overcome barriers to inclusion for children when they exist. Opportunity to experience a challenging and enjoyable preschool programme demands equitable access to qualified staff, equitable expenditure across settings and equitable access to wellqualified staff and resources, regardless of circumstances of birth. Real equity is about fairness in distribution of resources, social, cultural and economic.

\section{Conclusions}

A strong theme running through this article has been communities suffering hardship, deprivation and social exclusion from social care and welfare, health and preschool education. The strategy adopted by the not-for-profit organisations involved has been to work with the community rather than the individual children and families concerned, in order to address structural poverty and family dislocation. Building on the strengths of the community, the intention has been to tackle the conditions of poverty of the community members through provision of access to knowledge and advice, that is social capital, and provide preschool services for young children as a means to promote social justice.

Attention has also been drawn to inequity in a broader context where powerful and wealthy business communities seek to maintain a privileged preschool experience for the youngest members of their groups. Foucault (1977) drew attention to the micro-politics of power in the networks of connections, in this case interactions and relationships among preschool teachers, children and extended family members that served to cement their mutual interests.

An attempt has been made to expose the particular social and cultural practices that govern social interactions and in particular preschool educational circumstances, mediating the way in which people construct meaning, and to interpret these. A grounded theory approach was used to capture personal meanings associated with preschool experiences in conditions of extreme hardship and in relative wealth. Overall, the wider project analysis of relevant policy frameworks, national and international, and a sharing of video highlights with provincial officials led to the agreement that policy texts and the situated practices revealed were in line with aspirations of the new, democratic Republic of South Africa and provincial history, traditions and beliefs of Zulu people. That said, lack of qualified teachers for Grade $\mathrm{R}$ and preschool and lack of access to quality ECD training was acknowledged, though this had to be set in the context of broader social issues that intersected with poverty alleviation, job creation and other community or family upliftment. Inadequate resources in community-based and rural ECD, along with accreditation for practitioners working to culturally appropriate and indigenous models, needed addressing. Social-action models based on prevention through empowerment mobilised the community.

In these preschool communities, central themes associated with readiness, needs and play have been identified and espoused by participants. The focus on free play in the South African preschool programme suggests enjoyment, respite from work, support of emotional well-being and promotion of confidence and competence. In terms of readiness, the middle-class children from the for-profit preschool were already more ready for school than those disadvantaged children from the non-profit preschool settings. Burman (2008) has noted that an uncritical commitment to readiness maintains unequal treatment of children. As the young NGOsponsored teacher acknowledged, how could she administer to the individual needs of all of a large group of young, vulnerable children? Not only was a play pedagogy hard to uphold but it served to sustain inequality. It was also against the wishes of the parents and caregivers concerned, who called for more formal and structured teaching. Their aspirations were seen instead as a failure to engage with the preschool programme. Meanwhile, the celebration of their indigenous culture was taking place in the wider context of a changing and rapidly developing majority culture, represented by the for-profit preschool community. 
Reynolds (1989) identified a 'Matthew effect' in early learning, a term that is derived from the Gospel according to Matthew 25:29:

... for unto everyone that hath shall be given, and he shall have abundance; but from him that hath not shall be taken away even that which he hath.

Children showing limited progress in the early phases of teaching in basic subjects, he noticed, tended to show progressive falling behind over succeeding years. This raises a challenge for preschool teachers in South Africa to reexamine expectations of what young children could and should achieve in ECD. A broad consensus among ECD practitioners was that children learn from play in a context that is relatively free from work or academic constraints. At the same time, as observed, children may be excluded or 'othered' and experience learned helplessness (Maier \& Seligman 1976). The responsibility of the preschool teacher must be to remain alert to the contradictions and complexities of children's learning, development and play in the new South Africa and the role of preschool education in offsetting inequalities. Ultimately, success can be judged only in the extent to which these captured policy-to-practice community perspectives and stories of practitioners and children reach a wider and more powerful political audience.

\section{Acknowledgements Competing interest}

The author declares that she has no financial or personal relationship(s) that may have inappropriately influenced her in writing this article.

\section{References}

Alderson, P., 1995, Listening to children: Children, ethics and social research, Barnado's, Barkingside.

Alderson, P. \& Morrow, V., 2004, Ethics, social research and consulting with children and young people, Barnado's, Ilford.

Berger, P.L. \& Luckmann, T., 1991, The social construction of reality. A treatise in the sociology of knowledge, Penguin, London.

Bredekamp, S. \& Copple, C. (eds.), 1997, Developmentally appropriate practice in early childhood programs, National Association for the Education of Young Children, Washington, DC.

British Psychological Society, 2008, Ethics and standards, British Psychological Society, Leicester.

Brooker, L., 2002, Starting school: Young children learning cultures, Open University Press, Buckingham.

Burman, E., 2008, Deconstructing developmental psychology, 2nd edn., Routledge, London.

Burr, V., 2003, An introduction to social constructionism, 2nd edn., Routledge, London.

Christensen, P. \& James, A. (eds.), 2008, Research with children. Perspectives and practices, 2 nd edn., Routledge, London.

Corbin, J. \& Strauss, A., 2008, Basics of qualitative research. Grounded theory, procedures and techniques, 3rd edn., Sage, London.

Dawes, A., Bray, R. \& Van der Merwe, A. (eds.), 2007, Monitoring well-being: A South African rights-based approach, Human Sciences Research Council, Cape Town, South Africa.

Department of Basic Education, 2013, Overview of the lesson learned from the implementation of the national integrated plan for early childhood development in South Africa 2005-2010 in the basic education sector, Department of Basic Education, Social Development and Health, supported by UNICEF, Pretoria.

Ebrahim, H. \& Irvine, M., 2012, National curriculum framework birth to five, Department of Basic Education, Social Development and Health, supported by UNICEF, Pretoria.

Foucault, M., 1977, Discipline and punishment, Penguin, Harmondsworth.
Gielen, U.P. \& Roopnarine, J. (eds.), 2004, Childhood and adolescence: Cross-cultural perspectives and applications, Praeger, Westport, CT.

Gorski, P.C., 2014, 'Poverty, class and the cultivation of economically just education policy: The role of ideology', Research Intelligence, Autumn 125, 14-15.

Government of South Africa, 2005, National integrated plan for early childhood development in South Africa, 2005-2010, Department of Basic Education, Social Development and Health, supported by UNICEF, Pretoria.

Grieshaber, S., 2008, 'Interrupting stereotypes: Teaching and the education of young children', Early Education and Development 19(1), 91-97. https://doi. org/10.1080/10409280802068670

Grieshaber, S. \& McArdle, F., 2010, The trouble with play, Open University Press, Maidenhead.

Hall, K., Woolard, I., Lake, L. \& Smith, C., 2012, South Africa. Child gauge, Children's Institute, University of Cape Town, Cape Town.

Harkness, S. \& Super, C.M., 1992, 'Shared child care in East Africa: Socio-cultural origins and developmental consequences', in M.E. Lamb, K.J. Sternberg, C.P. Kwang \& A.G. Broberg (eds.), Child care in context: Socio-cultural perspectives, pp. 441-459, Erlbaum, Hillsdale, NJ.

James, A. \& Prout, A., 1997, Constructing and reconstructing childhood: Contemporary issues in the sociological study of childhood, Falmer, London.

Kaur, B., Quinlivan, K. \& Boyask, R., 2009, Educational enactments in a globalised world: Intercultural conversation, Sense, Rotterdam.

Lincoln, Y.S. \& Guber, E.G., 1985, Naturalistic inquiry, Sage, Beverly Hills, CA.

Maier, S.F. \& Seligman, M.E., 1976, 'Learned helplessness: Theory and evidence', Journal of Experimental Psychology 105(1), 3-46. https://doi.org/10.1037/00963445.105.1.3

Ngcobo, J., 2013, Overview of the lesson learned from the implementation of the national integrated plan for early childhood development in South Africa 2005-2010 in the basic education sector, Research Unit, Parliament to the Republic of South Africa, Cape Town.

Nsamenang, A.B., 1992, Human development in cultural context: A third world perspective, Sage, Newbury Park, CA.

Nsamenang, A.B., 2001, 'Indigenous view on human development: A West African perspective', in N.J. Smelser \& J. Schummaker (eds.), International encyclopedia of the social and behavioural sciences, pp. 7297-7299, Elsevier, London.

Nsamenang, A.B., 2004, Cultures of human development and education: Challenge to growing up in Africa, Nova, New York.

Nsamenang, A.B. \& Lamb, M.E., 1994, 'Socialization of Nso children in the Bamenda Grassfields of northwest Cameroon', in P.M. Greenmailed \& R.R Cocking (eds.) Cross-Cultural roots of minority child development, pp. 133-146, Erlbaum, Cross-Cultura
Hillsdale, NJ.

Pence, A.R., 1998, 'Reconceptualising ECCD in the majority world: One minority world perspective', International Journal of Early Childhood 30(2), 19-30. https://doi. perspective, International
org/10.1007/BF03185631

Pence, A.R. \& Nsamenang, A.B., 2008, A case for early childhood development in SubSaharan Africa, Working Papers in ECD 51, Bernard van Leer Foundation, The Hague, The Netherland.

Penn, H., 2005, Unequal childhoods. Young children's lives in poor countries, Routledge, London.

Reynolds, M.C., 1989, 'Students with special needs', in M.C. Reynolds (ed.), The knowledge base for the beginning teacher, pp.129-142, Pergamon, Oxford.

Robertson, S.L., 2014, 'Young people deserve more than a 'Winner takes all' approach to education', Research Intelligence, Autumn 125, 10-11.

Ryan, G.W. \& Bernard, H.R., 2000 'Data management an analysis methods', in N.K. Denzin \& Y.S. Lincoln (ed.), Handbook of qualitative research, 2nd edn., pp. 769-802, Sage, Thousand Oaks, CA.

Ryan, S.K., 2005, 'Freedom to choose: Examining children's experiences in choice time', in N. Yelland (ed.), Critical issues in early childhood education, pp. 99-114, Open University Press, Maidenhead.

Ryan, S.K. \& Grieshaber, S., 2005, 'Shifting from developmental to postmodern practices in early childhood teacher education', Journal of Teacher Education 56(1), 34-45. https://doi.org/10.1177/0022487104272057

Serpell, R., 1993, The significance of schooling: Life-journeys into an African society, Cambridge University Press, Cambridge.

Stainton Rogers, W., 2011, Social psychology, 2nd edn., Open University Press, Maidenhead.

Sutton-Smith, B., 1997, The ambiguity of play, Harvard University Press, Cambridge, MA.

UN, 1989, United Nations Convention on the Rights of the Child, United Nations Children's Fund, Geneva.

UNDP, 2014, Human development report 2014: Sustaining human progress: Reducing vulnerabilities and building resilience, UNDP, New York.

Viruru, R., 2001, Early childhood education: Postcolonial perspectives from India, Sage, London.

Walkerdine, V., 1984, 'Developmental psychology and the child-centred pedagogy: The insertion of Piaget into early education', in J. Henriques, W. Hollway, C. Urwin, C. Venn \& V. Walkerdine (eds.), Changing the subject: Psychology, social regulation and subjectivity, pp. 153-202, Methuen, London.

Woodhead, M., 1996, In search of the rainbow: Pathways to quality in large-scale programmes for young disadvantaged children, Bernard van Leer Foundation, The Hague, The Netherlands. 